\title{
Comparison of taper functions applied to eucalypts of varying genetics in Brazil: Application and evaluation of the penalized mixed spline approach
}

\begin{tabular}{|c|c|}
\hline Journal: & Canadian Journal of Forest Research \\
\hline Manuscript ID & cjfr-2017-0366.R2 \\
\hline Manuscript Type: & Article \\
\hline Date Submitted by the Author: & 06-Feb-2018 \\
\hline Complete List of Authors: & $\begin{array}{l}\text { Ferraco Scolforo, Henrique; North Carolina State University, Forestry and } \\
\text { Environmental Resources } \\
\text { McTague, John Paul; North Carolina State University, Forestry and } \\
\text { Environmental Resources } \\
\text { Regis Raimundo, Marcel; Granflor Agroflorestal } \\
\text { Weiskittel, Aaron; University of Maine, } \\
\text { Carrero, Omar; Granflor Agroflorestal } \\
\text { Soares Scolforo, Jose Roberto; Universidade Federal de Lavras - UFLA, } \\
\text { Forest Science }\end{array}$ \\
\hline Keyword: & $\begin{array}{l}\text { eucalyptus, stem form, volume, parametric regression, semi-parametric } \\
\text { regression }\end{array}$ \\
\hline $\begin{array}{r}\text { Is the invited manuscript for } \\
\text { consideration in a Special } \\
\text { Issue? : }\end{array}$ & N/A \\
\hline
\end{tabular}


$7{ }^{1}$ Corresponding author. Department of Forestry and Environmental Resources, North Carolina

8 State University, Raleigh, North Carolina, United States of America. 2820 Faucette Dr., Campus

$14{ }^{3}$ Granflor Agroflorestal. 1200 Av. Carlos Gomes, B. Mont Serrat, Porto Alegre 90480-001, 15 Brazil, marcelufla@gmail.com

$16{ }^{4}$ School of Forest Resources, University of Maine, Orono, Maine, United States of America. 175755 Nutting Hall. 04469-5755, aaron.weiskittel@maine.edu

${ }^{4}$ Department of Forest Science, Federal University of Lavras, Lavras, Minas Gerais, Brazil. 21 Campus Universitário, Campus Box 3037, LEMAF. 37200-000, jscolforo@dcf.ufla.br 


\section{Abstract}

23 Taper functions have been widely used with an existing array of model forms and methods.

24 However, comparisons of contrasting statistical methods have been more limited. This study 25 aimed to assess contrasting statistical approaches for achieving accurate stem taper and 26 individual tree volume predictions, with focus on the novel penalized mixed spline (PMS)

27 approach. The approaches were tested using four different eucalyptus genetic families planted in 28 Brazil. For comparison, the predictions of diameter outside bark (dob) and volume using a $5^{\text {th }}$ 29 degree polynomial, the polynomial of integer and fractional powers, a segmented taper function, 30 a variable exponent taper function, and a semi-parametric PMS were conducted. Comparisons 31 using the generalized functions of every stem taper function with genetic family as an extra 32 random component were also conducted. Data-splitting was used to test the accuracy of each 33 taper function. PMS and the generalized PMS were the most accurate for both dob and volume, 34 while the generalized PMS approach displayed more stable volume predictions along the stem. 35 The other approaches were more variable across the tree size classes examined. Overall, the 36 study highlights the applicability of the PMS methodology for predicting tree taper and volume 37 that warrants future assessment and application. 


\section{Introduction}

A combination of high quality data from forest inventory and precise techniques to evaluate the data is essential to provide the information needed for decision making at both the stand and forest levels. This key information is often derived from the use of a stem taper function. This function enables the description of the shape of the tree bole, which makes possible the merchandizing of multiple products from a specific forest (Gomat et al. 2011). profile studies (Ferreira 1999). However, one problem regarding the use of a fixed solid of revolution is that a tree displays different shapes along its stem. In 1903, Höjer developed the first taper function, which was applied to Picea abiens (L.) Karst. (Löetsch et al. 1973). Although the first taper function was developed in 1903, only in the 1970s did the interest for the development of more powerful approaches dramatically increase (Gomat et al. 2011). Over time, a variety of taper approaches have been used such as polynomials (Goulding and Murray 1976), variable exponent form (Demaerschalk 1972; Ormerod 1973; Kozak et al. 1988; Kozak 2004), and segmented polynomial (Max and Burkhart 1976; Parresol et al. 1987). Despite their wide use and varying model forms, comparisons of taper equation performance in predicting both stem form and volume for a given species is less common (Li and Weiskittel 2010).

The best approach for modeling stem taper has varied among regions and species. For example, Assis et al. (2001) studying taper functions applied to eucalyptus in Brazil suggested the desirable capability of polynomials, where the authors discussed the efficiency of the 66 polynomial of integer and fractional powers to describe the shape of the tree bole for older stands 67 and/or larger trees. Figueiredo-Filho et al. (1996) studying Pinus taeda in southern Brazil also 68 highlighted the consistent performance of the $5^{\text {th }}$ degree polynomial. Among 32 fitted taper 
69 functions, Rojo et al. (2005) described the superior behavior of the variable exponent form of 70 Kozak (2004) to predict the stem taper of Pinus pinaster Ait. in Galicia. They emphasized the

71 function's high flexibility and strong predictive capabilities. Developing a compatible stem

72 volume and taper equation system for three species in Turkey, Brooks et al. (2008) pointed out

73 the performance consistency and the satisfactory estimates provided by the segmented

74 polynomial taper function of Max and Burkhart (1976). For three conifer species in eastern

75 North America, Li and Weiskittel (2010) showed that the best taper equation varied depending

76 on species, available data, and whether accuracy for stem form and volume was desired, but

77 indicated that the Kozak (2004) model generally performed well.

Assis et al. (2001) pointed out the difficulty when using a single taper approach to

79 describe different species and a wide range of tree size classes. Bi (2000) associated this problem with the number of parameters of low biological interpretation in most taper equations.

81 Therefore, the most accurate taper function may be specific to the species, tree size class, and 82 region, which highlights the need for the development of a generalized and flexible approach.

83 This is particularly the case for eucalyptus plantations in Brazil, which have short rotations and a 84 dramatic change in the tree size from one year to another (Scolforo et al. 2016). Thus, a lack of 85 flexibility could easily result in highly biased estimates. In addition, the lack of studies assessing 86 the flexibility and stability of different taper functions across tree size classes is a major 87 shortcoming for plantations in this country.

Generally, traditional parametric approaches are used to fit stem taper equations. Semi89 parametric and nonparametric methods have also been used. This has included smoothing splines 90 (Lappi 2006), B-splines (Kublin et al. 2013), neural networks (Özçelik et al. 2010), and 91 generalized additive models (Robinson et al. 2011). Similar to the comparison of stem taper 
92 model forms, the assessment of the performance of parametric and nonparametric methods have

93 been less common. For example, Robinson et al. (2011) indicated that their semi-parametric 94 method had similar performance as a more traditional parametric approach for predicting whole95 stem volume, merchantable volume, number of logs, small-end diameter of the first log, and volume of the first log, while Özçelik et al. (2010) suggested that the nonparametric neural 97 network was superior to the parametric approach. To our knowledge, the semi-parametric approach of penalized splines has yet to be assessed for predicting stem taper.

Penalized splines, which are an evolution of the spline, are well known for avoiding 100 under/over fitting and poorly behaved estimation in the tails (Harrell 2015). However, since weights for its smooth function is based on a penalization criteria, inference might be difficult. 102 Pedan (2003) pointed out, however, that the penalized spline regression displays the same 103 solution when using mixed effects modeling, since this technique is closed related to smoothing. 104 Consequentially, the penalized mixed spline methodology might prove highly robust and flexible 105 for predicting stem taper and volume.

Despite the importance of eucalyptus plantations in Brazil, comparisons of contrasting 107 taper functions have been more limited. Therefore, this study aimed to develop and compare contrasting taper approaches applicable to four different and widely used eucalyptus genetic 109 families. In particular, interest was in the approach that resulted in more stable predictions when estimating both stem taper and individual tree volume across a range of tree size classes. Taper 111 functions were developed from the semi-parametric methodology of penalized mixed splines as 112 well as several alternative commonly used parametric model forms including the $5^{\text {th }}$ degree 113 polynomial, the polynomial of integer and fractional powers, the segmented polynomial of Max 114 and Burkhart (1976) and the variable exponent form of Kozak (2004). Specific research 
115 objectives were to: (1) fit each of these methods to each genetic family; (2) evaluate predictions

116 of both stem taper and volume; and (3) compare a family-specific approach to a generalized

117 approach that treated genetic family as a random effect. Our expectations were that the penalized

118 mixed spline would perform best for both stem taper and volume, while the generalized approach

119 would be superior to the genetic family-specific approach.

120

$121 \quad$ 2. Material and methods

122 2.1. Study area and database

123

The study was conducted on a population stratified with four different genetic families of

124 eucalyptus with total planted area of 20,000 ha, located in the municipality of Água Clara,

125 eastern Mato Grosso do Sul (MS) (Figure 1). The state of Mato Grosso do Sul is the sixth largest

126 state in Brazil, with an area greater than England. In recent past, MS has dramatically increased

127 its acreage in eucalyptus plantations. MS is now the second largest eucalyptus roundwood

128 producer state in Brazil (Painel Florestal 2015). The location of Água Clara is at 20²6'53" S and

$12952^{\circ} 52^{\prime} 40^{\prime \prime} \mathrm{W}$, with average elevation of $303 \mathrm{~m}$ and Aw Köppen climate classification. The mean

130 temperature is $26^{\circ} \mathrm{C}$, while the average annual rainfall is 1,350 $\mathrm{mm}$ (Alvares et al. 2013).

The study area is in flat lands, where the soils are predominantly Quartz-sand dystrophic

132 neosol, which are deep, excessively drained soils and presents low water retention capacity and

133 fertility. The database was composed of four different genetic families of eucalyptus, each

134 planted at $5.0 \times 2.6 \mathrm{~m}$ spacing, where precommercial thinning was applied when the plantations

135 were 2 years old. The plantations were different from the predominant status of Brazilian

136 industrial forests as the focus was not pulpwood and energy production, but saw-timber

137 production. A total of 590 trees, distributed in 117 stands and four genetic families, were bucked 
138 and scaled during 2012 to 2016 . An average of 5 trees per stand were selected, implying that the 139 selection of trees was balanced across different genetic families.

The plantations ages where trees were bucked and scaled range from 3.9 to 6.6 years

141 (Table 1). On each scaled tree, measurements of diameter at $1.30 \mathrm{~m}$ above ground (DBH), 142 diameter inside bark (dib), diameter outside bark (dob), bark thickness, total height (H) and 143 stump height were taken. Measurements representing the tree bole were also taken, where dob, 144 dib and bark thickness were measured at the stump height, at the middle height between the 145 stump and $1.3 \mathrm{~m}$, and after $1.3 \mathrm{~m}$ at every $2 \mathrm{~m}$ until the tree top.

147 Table 1 is here

148

Figure 1 is here

150

\subsection{Taper functions}

We developed and applied new taper functions using a penalized mixed spline

153 methodology, which were compared to the taper functions of the $5^{\text {th }}$ degree polynomial, 154 polynomial of integer and fractional powers, Max and Burkhart (1976), and Kozak (2004).

155 The analysis was performed in the software R (R Core Team 2015) with the package 156 nlme (Pinheiro et al., 2016) for fitting all the taper models. For all the approaches, within-stem 157 correlation and variance heteroskedasticity were accounted for using a first-order continuous 158 autocorrelation function $(\mathrm{CAR} 1)$ and power variance function. Each of these approaches is 159 described in more detail below. 
161

162

163

164

165

166

167

168

169

170

171

172

173

174

175

176

177

178

179

180

181

182

183

0

171

\subsection{1. $5^{\text {th }}$ degree polynomial}

The $5^{\text {th }}$ degree polynomial is the most commonly applied taper function in Brazil for eucalyptus due to its model form simplicity and acceptable precision (Sanquetta et al. 2015). The polynomial is a flexible continuous function that is used to describe the shape of the tree bole.

The $5^{\text {th }}$ degree polynomial was first introduced by Schöepfer in 1966 (Sanquetta et al. 2015):

$$
\frac{d_{i}}{D B H}=\left(\beta_{1}+b_{1}\right)\left(1-\frac{h_{i}}{H}\right)+\left(\beta_{2}+b_{2}\right)\left(1-\frac{h_{i}}{H}\right)^{2}+\beta_{3}\left(1-\frac{h_{i}}{H}\right)^{3}+\beta_{4}\left(1-\frac{h_{i}}{H}\right)^{4}+\beta_{5}\left(1-\frac{h_{i}}{H}\right)^{5}
$$

where $\beta_{j s}$ are the fixed coefficients to be estimated; $b_{1}$ and $b_{2}$ are the random coefficients based on each tree (stand) and stand, since the higher variability at the tree base; $d_{i}$ is the dob; $h_{i}$ is the stem height; other variables were already defined.

A single generalized function was fitted as well. This generalized function included genetic family as a random component so that $b_{1}$ and $b_{2}$ are the random coefficients based on each tree (stand), stand (genetic family) and genetic family.

While Equation (1) and its generalization are constrained to predict an upper-stem diameter $\mathrm{d}=0$ when $\mathrm{h}=\mathrm{H}$, most applications of the $5^{\text {th }}$ degree polynomial in Brazil possess an intercept term $b_{0}$ and hence do not contain this logical constraint.

\subsubsection{Polynomial of integer and fractional powers}

Hradetzky (1976) studied the best powers when describing the shape of the tree bole and suggested a polynomial with exponents ranging from 0.005 to 25 would be more suitable to describe stem taper that instead of the fixed $5^{\text {th }}$ degree polynomial (Assis et al. 2001). Exponents closer to zero were better at describing the tree base, while exponents of 20 and 25 were better for the top portion of the tree. The stepwise selection of the best exponents resulted from a 
184 combination of a maximum six coefficients that presented the highest F-test. The fitted 185 Hradetzky (1976) presents the general form:

186

(2) $\frac{d_{i}}{D B H}=\left(\beta_{1}+b_{1}\right)\left(1-\frac{h_{i}}{H}\right)^{p_{1}}+\left(\beta_{2}+b_{2}\right)\left(1-\frac{h_{i}}{H}\right)^{p_{2}}+\beta_{3}\left(1-\frac{h_{i}}{H}\right)^{p_{3}}+\beta_{4}\left(1-\frac{h_{i}}{H}\right)^{p_{4}}+\beta_{5}\left(1-\frac{h_{i}}{H}\right)^{p_{5}}+\beta_{6}\left(1-\frac{h_{i}}{H}\right)^{p_{6}}$

187

188

189

190

191

192

193

194

195

196

197

198

199

200

201

202

203

204

205

where $\beta_{j s}$ are the fixed coefficients to be estimated; $b_{1}$ and $b_{2}$ are the random coefficients based on each tree (stand) and stand. Since the highest variability is at the tree base; $p_{n}$ are the exponents ranging from 0.005 to 25 .

A generalized function that included genetic family as a random component was fitted, where $b_{1}$ and $b_{2}$ are the random coefficients based on each tree (stand), stand (genetic family) and genetic family. The selection of the best exponents was previously explained, however, a maximum of seven coefficients was employed in the generalized function.

\subsubsection{Max and Burkhart (1976)}

A very widely used taper function was developed by Max and Burkhart (1976), which models the transition from the frustum of neiloid to frustum of paraboloid at the lower part of the stem, and once again the transition of the frustum of paraboloid to cone in the upper part of the stem with one smooth continuous function. The points of transition from one solid form to another are called knots, and the lower knot associated with the change from frustum of neiloid to frustum of paraboloid generally occurs in the lower $12 \%$ of relative height or where $\mathrm{h}_{\mathrm{i}} / \mathrm{H}<$ 0.12. The transition from frustum paraboloid to cone generally occurs in the upper $25 \%$ of relative height or when the knot of $h_{i} / H$ exceeds 0.75. The Max and Burkhart (1976) segmented taper function can be expressed as: 
(3) $\left(\frac{d_{i}}{D B H}\right)^{2}=\beta_{1}\left(\frac{h_{i}}{H}-1\right)+\beta_{2}\left(\left(\frac{h_{i}}{H}\right)^{2}-1\right)+\left(\beta_{3}+b_{3}\right)\left(\alpha_{1}-\frac{h_{i}}{H}\right)^{2} I_{1}+\left(\beta_{4}+b_{4}\right)\left(\alpha_{2}-\frac{h_{i}}{H}\right)^{2} I_{2}$ cone in the upper part of the stem ( $75-85 \%$ of total height) to be estimated; $\alpha_{2}$ is the knot value of $h_{i} / H$ or point of transition between the frustum of neiloid and frustum of paraboloid in the

210 lower part of the stem (10-15\% of total height) to be estimated; $I_{1}$ is 1 if $h_{i} / H<\alpha_{1}$, otherwise $I_{1}$ is

212 and $b_{4}$ are the random coefficients based on each tree (stand) and stand following Cao and Wang 213 (2011).

A generalized segmented taper function was fitted by including the genetic family as one

217 (stand), stand (genetic family) and genetic family.

\subsubsection{Kozak (2004)}

A widely used variable exponent taper function was developed by Kozak (2004). He

222 a continuous taper function, the transition from the frustum of neiloid to frustum of paraboloid,

223 and from the frustum of paraboloid to cone are compensated by the exponent changes. The 224 Kozak taper function can be expressed as:

$$
d_{i}=\left(\alpha_{0}+a_{0}\right) D B H^{\alpha_{1}} H^{\alpha_{2}} X^{\left[\beta_{1} z^{4}+\beta_{2}(1 / \exp (D B H / H))+\left(\beta_{3}+b_{3}\right) X^{0.1}+\beta_{4}(1 / D B H)+\beta_{5} H^{Q}+\beta_{6} X\right]}
$$


226 where $X=\left(1-\left(\frac{h_{i}}{H}\right)^{1 / 3}\right) /\left(1-p^{1 / 3}\right), Q=\left(1-z^{1 / 3}\right), p=1.3 / H$ and $Z=\frac{h_{i}}{H} ; \alpha-\alpha_{2}, \beta_{1-} \beta_{6}$ are the fixed

227 coefficients to be estimated; $a_{0}$ and $b_{3}$ are the random coefficients based on each tree (stand) and

228 stand following Li et al. (2012); $p$ is the relative height where trees change from a neiloid to a 229 paraboloid, or the inflection point.

232 and $b_{3}$ are the random coefficients based on each tree (stand), stand (genetic family) and genetic 233 family.

\subsubsection{Penalized Mixed Spline}

The Max and Burkhart (1976) taper function has five restrictions or constraints and the

237 derivation is quite challenging. Following the Max and Burkhart (1976) concept, we wanted to 238 add another knot that includes the bottom portion of the stem. However, we employed a flexible 239 and more efficient way to express that, which is based on splined polynomial taper functions.

$$
\frac{d_{i}}{D B H}=\beta_{1}\left(1-\frac{h_{i}}{H}\right)+\beta_{2}\left(1-\frac{h_{i}}{H}\right)^{2}+\beta_{3} S+\sum_{k=1}^{K} u_{k}\left(\left(1-\frac{h_{i}}{H}\right)-k_{1}\right)_{+}^{2}
$$


247 where $\beta_{1}-\beta_{3}$ are the coefficients to be estimated; $S=\frac{D B H^{2} H}{10000} \ln \left(2-\frac{h_{i}}{H}\right) ; \mathrm{u}_{\mathrm{k}}$ are the knots

248 coefficients to be estimated; the + subscript operator infers that the function is only computed if $2491-\left(h_{i} / H\right)$ is larger than the knot value inside the parenthesis, otherwise the value is zero (hence 250 replacing the dummy variable used in the Max-Burkhart taper function).

251

Equation (6), which we defined as the penalized mixed spline approach (PMS), is a regression spline (Pedan 2003):

$$
y=X \beta+Z u+\varepsilon,[u, \varepsilon]^{T} \sim N\left(0, \operatorname{diag}\left(\sigma_{u}^{2} I, \sigma_{\varepsilon}^{2} I\right)\right)
$$

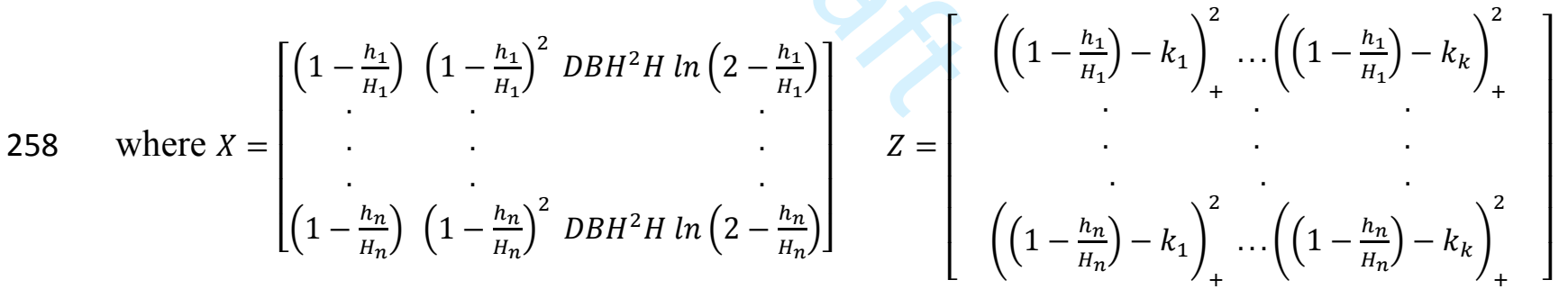

Finally, an expanded PMS taper function, which was a single generalized equation with coefficients associated with genetic family. use for volume estimation is extremely tedious, which makes its use inconvenient and susceptible to error. We suggest instead, the numerical integration of the taper function with small intervals and the use of Smalian's formula for volume estimation. 


\subsection{Goodness of fit}

Prior to fitting any taper function, the dataset was stratified by tree size class (every $10^{\text {th }}$ 270 quantile). Thus, $30 \%$ of the dataset were randomly removed from each tree size class for each 271 genetic family. The removed datasets for each genetic family were used for predictive validation. 272 For the predictive validation, the statistics of Mean Absolute Error (MAE), Mean Error (T) and 273 Root Mean Square Error (RMSE) were calculated for each of the four genetic families for each 274 taper approach. These three statistics were calculated when predicting stem taper (dob at any 275 stem height) and individual tree volume (cumulative individual tree merchantable volume).

$$
\operatorname{MAE}(\%)=\frac{\sum_{i=1}^{n}\left(\frac{\left|O_{i}-P_{i}\right|}{O_{i}}\right)}{n} 100
$$

$$
T(\%)=\frac{\sum_{i=1}^{n}\left(\frac{O_{i}-P_{i}}{O_{i}}\right)}{n} 100
$$

$$
R M S E=\sqrt{\left(\frac{\sum_{i=1}^{n}\left(O_{i}-P_{i}\right)^{2}}{n}\right)}
$$

where $\mathrm{n}$ is the number of observation; $O_{i}$ is the observed variable; $P_{i}$ is the estimated variable. generalized taper functions, and we then used the three different statistics to determine the best

284 approach. Therefore, to simplify the analysis, we simply ranked the performance of each taper function and then decided the best one when estimating stem taper and individual tree volume. 
For all approaches, stem volume estimation was based on numerical integration of

287 Smalian's formula. The different section lengths coincided with the exact locations where

288 observed measurements of the tree bole were taken. Graphical analysis for volume prediction

289 along the stem was also conducted to ensure the stability of each taper function. The R package

290 ggplot2 (Wickham 2009) was used to produce the graphical analysis.

291

$292 \quad$ 3. Results

$293 \quad$ 3.1. Performance of the taper functions for each genetic family

294 Since we fit a total of 25 equations, the fitted coefficients are presented in Supplemental

295 Materials. The retained coefficients were all significant at the $p=0.05$ level and were judge to be

296 important in describing the shape of the tree bole. When coefficients were not significant, they

297 were removed and the function was refitted to maintain parsimony.

298 High accuracy was achieved when estimating stem taper and individual tree volume

299 using all taper functions (Table 2). Estimates were generally accurate with low bias and the taper

300 functions were well behaved in describing the shape of the tree bole (Figure 2). Irrespective of

301 the genetic family and taper approach, the RMSE was never greater than $0.86 \mathrm{~cm}$ for dob

302 estimation and $0.019 \mathrm{~m}^{3}$ for individual tree volume estimation. In addition, $\mathrm{T}$ and MAE were 303 never greater than $6.5 \%$ and $10 \%$, regardless dob or volume estimation.

305 Table 2 is here

306

$307 \quad$ Figure 2 is here

308 
The statistics of Table 2 indicated similar estimates for all examined taper approaches.

310 Thus, we decided to rank the three statistics across the different taper approaches to determine

311 the one that performed better when predicting both stem taper and individual tree volume (Table

312 3). Overall, when estimating dob and individual tree volume, PMS and generalized PMS taper

313 functions performed slightly better, although all the approaches, particularly Kozak (2004) for

314 dob estimation, performed well. The generalized functions behaved worse than the functions

315 fitted to each genetic family, although in the PMS approach this behavior was not detected. PMS

316 and generalized PMS taper functions performed similarly, which is an indication of the better

317 behavior of this approach when compared to others.

318

$319 \quad$ Table 3 is here

320

321 3.2. Performance of the taper functions when stratifying the dataset according to tree

322 size

Although PMS and generalized PMS taper functions performed better when predicting 324 stem taper and individual tree volume, a further investigation was needed to assess how the taper 325 functions performed across a range tree size classes, particularly for volume. When stratified by 326 three size classes ( $33^{\text {th }}$ quantile, $33^{\text {th }}$ to $67^{\text {th }}$ quantile, and $67^{\text {th }}$ to $100^{\text {th }}$ quantile of DBH), the 327 results indicated low bias and high accuracy of all taper functions across the diameter size 328 classes (Table 4). 
When ranking the taper functions, it was observed that their behavior were quite different

333 across the different size classes (Table 5). For instance, the taper functions of Hradetzky (1976),

334 Max and Burkhart (1976), and Kozak (2004) performed well for average-sized and larger trees, 335 while the generalized Kozak (2004) performed well for smaller and larger trees. In contrast, the

$3365^{\text {th }}$ degree polynomial taper function was never observed as one of the best taper functions for 337 any tree size class. The generalized PMS and PMS models were consistently ranked as the best 338 or second best approaches for the evaluated statistics. In particular, the total for each approach 339 indicated that generalized PMS and PMS were the best taper approaches to describe individual 340 tree volume with PMS ranked higher for small and average trees and the generalized PMS for 341 larger trees. Since the generalized PMS and PMS were always high ranked across the examined 342 tree size classes, this demonstrated the greater flexibility of the PMS methodology when 343 compared to other taper approaches.

Table 5 is here

Finally, an examination of the performance of the taper models when estimating volume 348 along the stem was conducted. Generalized PMS and PMS were observed to perform better 349 when estimating the volume from stump to tree top (Figure 3). The generalized PMS behaved 350 especially better along the stem profile, which can be highlighted by its accurate and stable 351 estimates especially when predicting the volume of the first (lower) $40 \%$ of the tree height. This 352 behavior indicates that this taper approach produces accurate estimates for the portion of the tree 353 where volume is higher. The other taper functions also presented realistic behavior, although the $3545^{\text {th }}$ degree polynomial, Hradetzky (1976) Kozak (2004), Max and Burkhart (1976) and their 355 generalized functions displayed overall more unstable predictions. 
The higher estimation errors noticed for genetic family four might be more indicative of a

357 lack of a suitable sample size to capture its variability, since this genetic family presents the 358 highest variation according to tree size (Table 1) and fewer trees were bucked and scaled to 359 represent such variability when compared to the other genetic families.

\section{Figure 3 is here}

362

\subsection{Sampling distribution of the error statistics and testing of the inclusion of the} variable tree size in the PMS approach

Since the PMS approach as a generalized function had the overall best results, this section

366 focused on the analysis of the robustness of this approach. Robustness is inspected with respect

367 to error distributions and the precision gain by including a tree size variable in the taper function.

First, a total of 10,000 random samples using the non-parametric bootstrap technique were generated. These random samples allowed the estimation of the sampling distribution of the T, MAE and RMSE statistics when applied to evaluate the cumulative individual tree volume

371 (Figure 4 and Table 6). Overall, the approach gave high accuracy and low bias associated with 372 the estimates. Confidence intervals for T, MAE and RMSE at a 95\% confidence level displayed 373 short interval lengths, which reinforced the accuracy of the predictions generated from the PMS 374 approach. Differently from the previous analysis, however, the overall statistics accounted for all 375 genetic families instead of the specific genetic family evaluation. 


\section{Figure 4 is here}

For the PMS approach, we have proposed the inclusion of a variable related to the tree size to better estimate stem taper and tree volume. It was hypothesized that this variable reflects the stand density effect in plantations with same spacing and allow increasing the accuracy of the

384 volume predictions. It is obvious how the inclusion of such variable allow better predictions for 385 each genetic family, especially of the first (lower) $40 \%$ of the tree height (Figure5). This is a critical factor that validates the use of such a variable, since this is the most valuable part of the tree. The exception is the genetic family 4. However, the lack of ideal sample size, previously mentioned, circumvents a better fit for this genetic family.

\section{Figure 5 is here}

Testing the Full PMS approach over different genetic families also indicated better results

by using the specific coefficients for the genetic families in the quadratic expression instead of 394 the average fitted coefficients. The specific coefficients for the quadratic expression are 395 presented in Supplemental Materials.

\section{4. Discussion}

The accurate description of the shape of the tree bole is critical for assessing multiple products generated by a specific forest and it is quite challenging for eucalyptus species where

400 stem taper is constantly changing (Gomat et al. 2011). In this study, we applied 10 different 401 approaches to modeling taper with an extensive database containing four genetic families widely 
402 planted in a region of great forestry expansion in recent years (Painel Florestal 2015). The 403 analysis highlighted the PMS methodology (in both family-specific and generalized form) as 404 capable to effectively describe the shape of the tree bole, since PMS and generalized PMS 405 approaches displayed greater flexibility and stability when estimating stem taper and individual 406 tree volume across the range of tree size classes.

407 To our knowledge, this is the first application of a PMS methodology for predicting stem 408 taper, although some studies have already used other spline methodologies (Kublin et al. 2013; 409 Kuželka and Marušák 2014a; Kuželka and Marušák 2014b). Kuželka and Marušák (2014a), for 410 instance, applied several spline approaches for stem profile studies with Norway spruce (Picea 411 abiens (L.) Karst.), and the authors found the best results when applying the local interpolation 412 spline known as Catmull-Rom. Compared to these other spline approaches, we believe PMS 413 offers several advantages, particularly ease of estimation and prediction.

Accurate and low biased estimates are desirable for the selected taper function when 415 estimating total volume and dob ( $\mathrm{Li}$ et al. 2012). However, a close examination in the behavior 416 of the volume predictions along the stem is critical ( $\mathrm{Li}$ and Weiskittel 2010), especially for the 417 first (lower) portion of the tree, where the most valuable tree products originate. The PMS and 418 generalized PMS approaches displayed stable predictions along the stem profile, except for 419 genetic material 4. However, the generalized PMS performed best for this genetic family when 420 compared to other approaches. We highlight the overall high stability of generalized PMS 421 predictions. Since the addition of the genetic family as random effect provided improved stability 422 for volume predictions, this result indicates that a single generalized model for eucalyptus can be 423 used, which is similar to the findings of Trincado and Burkhart (2006). 
Given the noteworthy characteristics and performance of the generalized PMS model, we

425

426

427

428

429

430

431

432

433

434

435

436

437

438

439

440 441 increase of precision.

442

443

444

445

446

suggest how the results can be generalized for other genetic families. Both Lynch et al. (2005) and Trincado and Burkhart (2006) have proposed calibration methods for new observations using a reduced sample size of 5-6 trees. Their methodology works well for linear mixed models with one class (cluster) type variable. The generalized PMS model presented here has two class or cluster type variables; namely genetic family and knots. The inverted variance-covariance matrix in this case is complex, leading to a tedious calibration procedure. We suggest that when a new genetic family is deployed, even with only 5-6 sample trees, that the entire generalized PMS model be refitted. In this way, it is possible to preserve the shrinkage properties of the knots and penalty function, while calibrating the taper model to the new genetic family.

Combining the advantages mentioned above, including the good accuracy and low bias when individually estimating the cumulative volume and stem taper, and the great stability when predicting volume along the stem, the generalized PMS model can efficiently describe the shape of the tree bole for ages 4-7 and for all genetic families. This is an innovative result of significant importance as individual taper functions are customarily fit for every forest compartment and for each one-year age class in Brazil (Kohler et al. 2016). Additionally, including a tree size variable in the PMS approach predicts the stand density effect in plantations which contributes to the

The inclusion of S or size independent variable in the generalized PMS equation, where $S=\frac{D B H^{2} H}{10000} \ln \left(2-\frac{h_{i}}{H}\right)$, serves as a proxy for the age variable as well. While the effect of size or age is strongest at the base of the tree, larger trees at a given relative height, display more taper. While the fitting data set of this study, contained only a single spacing, namely $5.0 \times 2.6 \mathrm{~m}$, it is safe to state that stand of higher stem density will contain trees of smaller breast height diameters 
447 and smaller live crown ratios, resulting in better stem profile. The recession of the live crown 448 however, can be attenuated by intensive silvicultural practices such as fertilization.

450 using the PMS approach for any other commercial tree species. The flexibility of such approach

451 for accurately predicting stem taper and individual tree volume of eucalypts of varying genetics

452 merits attention. Eucalypts face dramatic annual change in tree size due to their high growth rate

453 (Scolforo et al. 2017). To our knowledge this rapid change in the stem taper is not observed for

454 other tree commercial species. Since PMS displays the ability to accurately model the change of 455 eucalyptus stem taper, this approach is likely suitable for any other commercial tree species.

456 Gomat et al. (2011) discussed the necessity of developing taper functions that can display 457 unbiased results if fitted for any tree species and it is possible to infer that the PMS approach 458 presents this capability.

459 The other taper functions displayed a suitable behavior as well. The $5^{\text {th }}$ degree 460 polynomial and Hradezky (1976) are the most widely applied taper functions for eucalyptus 461 forest in Brazil, since they display simplicity and ease of estimation (Assis et al. 2001). A closer 462 examination of these approaches indicated relatively accurate and low biased estimates, 463 however, unstable volume predictions along the stem were observed either using the generalized 464 functions or specific fits to each genetic family. Ribeiro and Andrade (2016) compared the 465 performance of different stem taper functions for eucalyptus in the state of Tocantins in Brazil 466 and indicated more reliable estimates for the taper functions of the $5^{\text {th }}$ degree polynomial and 467 Hradetzky (1976). Although these two taper functions displayed the best fit results, the authors 468 reported, however, a high degree of uncertainty when estimating volume along the stem. 
Several studies have reported the performance of the Kozak (1969) taper function for

470

471

472

473

474 (2004) and generalized Kozak (2004) taper functions were fitted for the first time for eucalyptus

475 forests in Brazil. The innovative results suggested accurate and low biased estimates of the

476 Kozak (2004) especially for average and larger trees, while the generalized Kozak (2004)

477 performed best for smaller and larger trees. These taper functions, however, displayed unstable

478 volume predictions along the stem for some genetic families, which can compromise the quality

479 of predictions when assessing the multiple product potentials of a forest. Schröder et al. (2014)

480

481

482

483

484

485

486

487

488

489

490

491 noticed similar behavior when applying the Kozak (2004) taper function to slash pine (Pinus elliottii) in Brazil.

Finally, the segmented taper function of the Max and Burkhart (1976) approach, which was high ranked for averaged and larger trees, seemed to display unstable predictions of volume along the stem. Similar unstable predictions were observed when applying the generalized taper function. These results were already observed by Souza et al. (2008), where the authors applied the Max and Burkhart (1976) taper function to eucalyptus plantations in Brazil.

Future studies using the PMS approach developed in this study should provide additional evaluation with different species, management regimes, and tree spacing in order to reinforce the flexible nature of the PMS approach. 


\section{$492 \quad 5 . \quad$ Conclusions}

493

494

495

496

497

498

499

500

501

502

503

504

505

506

507

508

509

510

511

512

The 5th degree polynomial, generalized 5th degree polynomial, Hradetzky (1976), generalized Hradetzky (1976), Kozak (2004), generalized Kozak (2004), Max and Burkhart (1976), generalized Max and Burkhart (1976), PMS and generalized PMS approaches performed well when predicting stem taper and individual tree volume. The PMS and generalized PMS approaches however, displayed the best performance among all the tested approaches. These models were best for accurately predicting volume for all tree size classes, which is indicative of the flexible behavior of the PMS methodology. In particular, the generalized PMS displayed the greatest stability for volume estimation along the stem as opposed to the other generalized functions. In addition, this taper approach enabled the use of a single generalized model to describe the shape of the tree bole for any genetic family regardless age class and allows calibration using relatively few observations for a new genetic family. Finally, the PMS methodology presented in this study was highly efficient for describing both stem form and volume, while being relatively easy to fit. Consequently, its application in future studies is recommended.

\section{Acknowledgments}

The authors are especially grateful to the Granflor Agroflorestal, Forest Management Laboratory (LEMAF), Conselho Nacional de Desenvolvimento Científico e Tecnológico (CNPq) and Coordenação de Aperfeiçoamento de Pessoal de Nível Superior (CAPES). 


\section{References}

Alvares, C.A., Stape, J.L., Sentelhas, P.C., Goncalves, J.L.M., and Sparovek, G. 2013. Köppen's climate classification map for Brazil. Meteorol. Z. 22 (6): 711-728.

Assis, A.L., Scolforo, J.R.S., Mello, J.M., Acerbi Jr, F.W., and Oliveira, A.D. 2001. Comparison between segmented and non-segmented polynomial models in the estimates of diameter and merchantable volume of Pinus taeda. Cerne 7 (1): 20-40.

Bi, H.Q. 2000. Trigonometric variable-form taper equations for Australian Eucalypts. For. Sci. 46(3): 397-409.

Brooks, J.R., Jiang, L., and Ozcelik, R., 2008. Compatible stem volume and taper equations for Brutian pine, Cedar of Lebanon, and Cilicica fir in Turkey. For. Ecol. Manage. 256: 147-151.

Cao, Q.V., and Wang, J. 2011. Calibrating fixed- and mixed-effects taper equations. For. Ecol. Manag. 262, 671-673.

Demaerschalk, J.P. 1972. Converting volume equations to compatible taper equations. For. Sci. 18 (3): $241-245$.

Ferreira, S.O. 1999. Stem profile study of Eucalyptus grandis e Eucalyptus cloeziana. M.Sc. thesis, Department of Forest Science, Federal University of Lavras, Lavras, Brazil. 
Figueiredo Filho, A., Borders, B.E., and Hitch, K.L 1996. Taper equations for Pinus taeda plantations in southern Brazil. For. Ecol. Manage. 83 (1/2): 36-46.

Figueiredo Filho, A., and Schaaf, L.B. 1999. Comparison between predicted volumes estimated by taper equations and true volumes obtained by the water displacement technique (xylometer). Can. J. For. Res. 29: 451-461

Gomat, H.Y., Deleporte, P., Moukini, R., Mialounguila, G., Ognouabi, N., Saya, A.R., Vigneron, P., and Saint-Andre, L. 2011. What factors influence the stem taper of Eucalyptus: growth, environmental conditions, or genetics? Ann. For. Sci. 68: 109-120.

Goulding, C.J., and Murray, J.C. 1976. Polynomial taper equations that are compatible with tree volume equations. New Zeal. J. For. Sci. 5 (3): 313-322.

Harrell, F. 2015. Regression Modeling Strategies. 2nd ed. Springer, Dordrecht, pp. 24-28.

Kohler, S.V., Koehler, H.S., Figueiredo Filho, A., Arce, J.E., and Machado, S.A. 2016. Evolution of tree stem taper in Pinus taeda stands. Ciência Rural 46 (7): 1185-1191.

Kozak, A., Munro, D.D., and Smith, J.H.G. 1969. Taper functions and their application in forest inventory. For. Chron. 45(4): 278-283. 
Kozak, A. 1998. Effects of upper stem measurements on the predictive ability of a variableexponent taper equation. Can. J. For. Res. 28: 1078-1083.

Kozak, A. 2004. My last words on taper equations. For. Chron. 80(4): 507-515.

Kublin, E., Breidenbach, J., and Kändler, G. 2013. A flexible stem taper and volume prediction method based on mixed-effects B-spline regression. Eur. J. For. Res. 132(5-6): 983-997.

Kuželka, K., and Marušák, R. 2014a. Comparison of selected splines for stem form modeling: A case study in Norway spruce. Ann. For. Res. 57(1): 137-148.

Kuželka, K., and Marušák, R. 2014b. Use of nonparametric regression methods for developing a local stem form model. J. For. Sci. 60 (11): 464-471.

Lappi, J. 2006. A multivariate, nonparametric stem-curve prediction method. Can. J. For. Res. 36(4): 1017-1027.

Li, R., Weiskittel, A.R., Dick, A.R., Kershaw Jr., J.A., and Seymour, R.S. 2012. Regional stem taper equations for eleven conifer species in the Acadian Region of North America: Development and assessment. North J. Appl. For. 29(1): 5-14. 
Li, R., and Weiskittel, A.R. 2010. Comparison of model forms for estimating stem taper and volume in the primary conifer species of the North American Acadian Region. Ann For. Sci. 67(3): 302 .

Loetsch, F., Zohrer, F., and Haller, K.E. 1973. Forest inventory, BLV, München.

Lynch, T., Holley, A.G., and Stevenson, D.J. 2005. A random-parameter height-Dbh model for cherrybark oak. S. J. Appl. For. 29(1): 22-26.

Max, T.A., and Burkhart, H.E. 1976. Segmented polynomial regression applied to taper functions. For. Sci. 22(3): 283-289.

McTague, J.P. 1992. Enhanced estimates of total volume with any single upper-stem measurement. For. Ecol. Manage. 48: 55-67.

Omerod, D.W. 1973. A simple bole model. For. Chron. 49 (3): 136-138.

Özçelik, R., Diamantopoulou, M.J., Brooks, J.R., and Wiant, H.V. 2010. Estimating tree bole volume using artificial neural network models for four species in Turkey. J. Environ. Manag. 91(3): 742-753.

Painel Florestal. 2015. Website official da Panel Florestal [online]. Available from http:/ftp://www.painelflorestal.com.br. [accessed 12 June 2017]. 
Parresol, B.R., Hotvedt, J.E., and Cao, Q.V. 1987. A volume and taper prediction system for bald cypress. Can. J. For. Res. 17 (3): 250-259.

Pedan, A. 2003. Smoothing with SAS Proc Mixed [online]. Available from http://www2.sas.com/proceedings/sugi28/268-28.pdf [accessed 12 June 2017].

Pinheiro, J., Bates, D., DebRoy, S., Sarkar, D., and R Core Team. 2016. nlme: Linear and nonlinear mixed effects models [online]. Available from https://cran.rproject.org/web/packages/nlme/nlme.pdf. [accessed 12 July 2017].

R Core Development Team. 2015. R: A language and environment for statistical computing. R Foundation for Statistical Computing, Vienna, Austria. ISBN 3-900051-07-0. Available online: http://www.r-project.org/ [accessed 12 December 2016].

Ribeiro, J.R., and Andrade, V.C.L. 2016. Stem Profile Equations for the Eucalyptus camaldulensis Dehnh in South Central Tocantins. Floresta e Ambiente 23(4): 534-543.

Robinson, A.P., Lane, S.E., and Thérien, G. 2011. Fitting forestry models using generalized additive models: a taper model example. Can. J. For. Res. 41(10): 1909-1916.

Rojo, A., Perales X., Sanchez-Rodriguez, F., Alvarez-Gonzalez, J.G., and von Gadow, K. 2005. Stem taper functions for maritime pine (Pinus pinaster Ait.) in Galicia (Northwestern Spain) Eur. J For. Res. 124: 177-186. 
Sanquetta, C.R., Sanquetta, M.N.I., Corte, A.P.D, Péllico Netto, S., Wojciechowski, J., and Rodrigues, M.A. 2015. Modeling the apparent volume of bamboo culms from Brazilian plantation. Afric. J. Agric. Res. 10 (42): 3977-3986.

Scolforo, H.F., Neto, F.C., Scolforo, J.R.S., Burkhart, H., McTague, J.P., Raimundo, M.R., Loos, R.A., Fonseca, S., and Sartorio, R.S. 2016. Modeling dominant height growth of eucalyptus plantations with parameters conditioned to climatic variations. For. Ecol. Manag. 380: 182-195.

Scolforo, H.F., Scolforo, J.R.S., Stape, J.L., McTague, J.P., Burkhart, H., McCarter, J., Neto, F.C., Loos, R.A., and Sartorio, R.S., 2017. Incorporating rainfall data to better plan eucalyptus clones deployment in eastern Brazil. For. Ecol. Manage. 391: 145-153.

Schröder, T., Arnoni, E.C., Valerio, A.F., and Lisboa, G.S. 2015. Taper equations for Pinus elliottii Engelm. in Southern Paraná, Brazil. For. Sci. 61(2): 311-319.

Souza, C.A.M., Silva, G.F., Xavier, A.C., Chichorro, J.F., Soares, C.P.B., and Souza, A.L. 2008. Evaluation of segmented taper models in the estimation of height and merchantable volume of Eucalyptus sp. bole. Árvore 32 (3): 453-463.

Trincado, G., and Burkhart, H.E. 2006. A generalized approach for modeling and localizing stem profile curves. For. Sci. 52: 670-682. 
Wickham, H. 2016. ggplot2. [online]. Available from https://cran.rproject.org/web/packages/ggplot2/ggplot2.pdf. [accessed 12 July 2017]. 
Table 1. Descriptive statistics and number of scaled trees in each age-class for each genetic family of the eucalyptus plantations.

\begin{tabular}{|c|c|c|c|c|c|c|c|c|c|c|c|c|c|c|c|c|c|c|}
\hline \multirow{2}{*}{$\begin{array}{l}\text { Genetic } \\
\text { Family }\end{array}$} & \multirow{2}{*}{ Data } & \multicolumn{5}{|c|}{$\begin{array}{c}\text { Age of bucked and scaled trees } \\
\text { (years) }\end{array}$} & \multicolumn{4}{|c|}{ DBH (cm) } & \multicolumn{4}{|c|}{$\mathbf{H}(\mathbf{m})$} & \multicolumn{4}{|c|}{$\mathbf{V}\left(\mathbf{m}^{\mathbf{3}}\right)$} \\
\hline & & 4 & 5 & 6 & 7 & Total & Mean & SD & Min. & Max. & Mean & SD & Min. & Max. & Mean & SD & Min. & Max. \\
\hline \multirow{2}{*}{1} & Fit. & 2 & 21 & 96 & 2 & 121 & 19.1 & 3.2 & 13.1 & 25.6 & 26.8 & 2.7 & 20.1 & 32.2 & 0.37 & 0.14 & 0.12 & 0.72 \\
\hline & Val. & 1 & 7 & 32 & 1 & 41 & 19.6 & 3.4 & 13.4 & 27.4 & 27 & 2.6 & 21.6 & 30.4 & 0.39 & 0.13 & 0.14 & 0.78 \\
\hline \multirow{2}{*}{2} & Fit. & - & 23 & 114 & 2 & 139 & 18.8 & 3.4 & 13.1 & 27.9 & 25.5 & 3.2 & 16.4 & 31.7 & 0.34 & 0.15 & 0.10 & 0.80 \\
\hline & Val. & - & 8 & 37 & 1 & 46 & 18.8 & 3.2 & 13.6 & 24.4 & 25.3 & 2.9 & 16.4 & 32.1 & 0.34 & 0.14 & 0.11 & 0.62 \\
\hline \multirow{2}{*}{3} & Fit. & - & 30 & 88 & 24 & 142 & 19.2 & 3.5 & 12.4 & 27.4 & 25.4 & 2.6 & 18.3 & 31.8 & 0.34 & 0.14 & 0.07 & 0.72 \\
\hline & Val. & - & 10 & 29 & 8 & 47 & 19 & 3.4 & 11.2 & 26.8 & 25.3 & 2.5 & 18.7 & 29.5 & 0.33 & 0.13 & 0.06 & 0.64 \\
\hline \multirow{2}{*}{4} & Fit. & - & - & 10 & 30 & 40 & 18.3 & 5.1 & 10 & 26.5 & 21.9 & 4.2 & 13.8 & 28.5 & 0.27 & 0.17 & 0.05 & 0.65 \\
\hline & Val. & - & - & 4 & 10 & 14 & 18.6 & 5.1 & 11 & 26.6 & 22.3 & 3.3 & 15.4 & 28 & 0.28 & 0.15 & 0.07 & 0.65 \\
\hline
\end{tabular}

SD: standard deviation; Min.: minimum; Max.: maximum; V: total volume outside bark; Fit.: fitting dataset; and

Val.: validation dataset. Genetic Family: 1 (E. urograndis), 2 (E. urograndis), 3 (E. urograndis), 4 (E. urograndis). 
Table 2. Accuracy statistics (T, MAE, and RMSE) applied to evaluate the dob (cm) and individual tree volume $\left(\mathrm{m}^{3}\right)$ estimation for the taper functions.

\begin{tabular}{|c|c|c|c|c|c|c|c|}
\hline \multirow{2}{*}{ Genetic family } & \multirow{2}{*}{ Taper functions } & \multicolumn{3}{|c|}{ Validation - dob (cm) } & \multicolumn{3}{|c|}{ Validation - volume $\left(\mathrm{m}^{3}\right)$} \\
\hline & & $\mathrm{T}(\%)$ & MAE (\%) & RMSE (cm) & T (\%) & MAE (\%) & RMSE $\left(\mathrm{m}^{3}\right)$ \\
\hline \multirow{10}{*}{1} & $5^{\text {th }}$ degree Polynomial & -1.22 & 6.46 & 0.71 & -1.58 & 4.56 & 0.018 \\
\hline & G. $5^{\text {th }}$ degree Polynomial & 0.56 & 6.59 & 0.73 & 0.04 & 4.61 & 0.016 \\
\hline & Hradetzky (1976) & -1.16 & 7.14 & 0.73 & -1.24 & 4.51 & 0.018 \\
\hline & G. Hradetzky (1976) & -0.45 & 6.99 & 0.71 & 0.21 & 4.48 & 0.016 \\
\hline & Kozak (2004) & -1.57 & 6.76 & 0.65 & -0.94 & 4.23 & 0.015 \\
\hline & G. Kozak (2004) & -1.16 & 6.86 & 0.69 & -0.06 & 4.25 & 0.015 \\
\hline & Max and Burkhart (1976) & -2.98 & 7.61 & 0.70 & -0.91 & 4.37 & 0.018 \\
\hline & G. Max and Burkhart (1976) & -1.83 & 7.69 & 0.73 & 0.18 & 4.59 & 0.017 \\
\hline & PMS & -0.81 & 6.22 & 0.66 & -0.91 & 4.26 & 0.015 \\
\hline & G. PMS & -0.17 & 6.19 & 0.69 & -1.09 & 4.30 & 0.014 \\
\hline \multirow{10}{*}{2} & $5^{\text {th }}$ degree Polynomial & 1.44 & 6.72 & 0.79 & 0.05 & 4.46 & 0.015 \\
\hline & G. $5^{\text {th }}$ degree Polynomial & 2.56 & 6.88 & 0.81 & 1.62 & 4.69 & 0.016 \\
\hline & Hradetzky (1976) & 1.18 & 7.39 & 0.77 & 0.29 & 4.44 & 0.015 \\
\hline & G. Hradetzky (1976) & 1.83 & 7.11 & 0.76 & 1.83 & 4.64 & 0.016 \\
\hline & Kozak (2004) & 0.07 & 6.46 & 0.73 & -0.14 & 4.40 & 0.015 \\
\hline & G. Kozak (2004) & 1.94 & 6.65 & 0.75 & 1.24 & 4.31 & 0.016 \\
\hline & Max and Burkhart (1976) & -1.38 & 7.41 & 0.78 & 0.22 & 4.46 & 0.016 \\
\hline & G. Max and Burkhart (1976) & 0.55 & 7.24 & 0.79 & 1.55 & 4.71 & 0.016 \\
\hline & PMS & 1.53 & 6.41 & 0.73 & -0.07 & 4.25 & 0.014 \\
\hline & G. PMS & 1.46 & 6.40 & 0.72 & -0.78 & 4.27 & 0.014 \\
\hline \multirow{10}{*}{3} & $5^{\text {th }}$ degree Polynomial & -2.97 & 7.52 & 0.84 & -1.17 & 4.91 & 0.018 \\
\hline & G. $5^{\text {th }}$ degree Polynomial & -3.98 & 7.84 & 0.86 & -1.56 & 4.94 & 0.019 \\
\hline & Hradetzky (1976) & -1.61 & 7.49 & 0.82 & -0.96 & 4.85 & 0.018 \\
\hline & G. Hradetzky (1976) & -4.30 & 7.71 & 0.80 & -1.35 & 4.88 & 0.019 \\
\hline & Kozak (2004) & -2.63 & 6.88 & 0.72 & -1.49 & 4.83 & 0.015 \\
\hline & G. Kozak (2004) & -4.05 & 7.59 & 0.71 & -1.69 & 4.82 & 0.015 \\
\hline & Max and Burkhart (1976) & -4.64 & 8.85 & 0.82 & -0.92 & 4.81 & 0.017 \\
\hline & G. Max and Burkhart (1976) & -6.43 & 9.85 & 0.85 & -1.58 & 4.92 & 0.018 \\
\hline & PMS & -2.53 & 6.83 & 0.72 & -1.19 & 4.73 & 0.015 \\
\hline & G. PMS & -2.76 & 6.92 & 0.72 & -1.59 & 4.82 & 0.015 \\
\hline \multirow{10}{*}{4} & $5^{\text {th }}$ degree Polynomial & 0.08 & 7.80 & 0.77 & 2.39 & 4.81 & 0.013 \\
\hline & G. $5^{\text {th }}$ degree Polynomial & -3.97 & 7.84 & 0.85 & -4.91 & 6.46 & 0.017 \\
\hline & Hradetzky (1976) & 1.68 & 9.37 & 0.80 & 2.37 & 4.87 & 0.013 \\
\hline & G. Hradetzky (1976) & -4.30 & 7.71 & 0.80 & -4.64 & 6.26 & 0.017 \\
\hline & Kozak (2004) & 0.80 & 6.61 & 0.76 & 2.06 & 5.22 & 0.018 \\
\hline & G. Kozak (2004) & -4.05 & 7.59 & 0.71 & -4.85 & 6.61 & 0.016 \\
\hline & Max and Burkhart (1976) & -1.26 & 7.95 & 0.76 & 2.11 & 4.94 & 0.013 \\
\hline & G. Max and Burkhart (1976) & -6.43 & 9.85 & 0.85 & -5.11 & 6.54 & 0.014 \\
\hline & PMS & 0.33 & 7.64 & 0.77 & 2.15 & 5.13 & 0.016 \\
\hline & G. PMS & -0.76 & 7.66 & 0.76 & -0.42 & 5.01 & 0.012 \\
\hline
\end{tabular}

G.: Generalized 
Table 3. Rank of each the taper models examined in this analysis based on T (\%), MAE (\%), and RMSE. These were calculated for dob $(\mathrm{cm})$ at multiple stem heights and individual tree volume $\left(\mathrm{m}^{3}\right)$ for the four genetic families.

\begin{tabular}{|c|c|c|c|c|c|c|c|c|c|c|c|c|c|c|c|c|c|c|c|c|c|}
\hline \multirow{2}{*}{$\begin{array}{l}\text { Genetic } \\
\text { family }\end{array}$} & \multirow{2}{*}{ Statistic } & \multicolumn{2}{|c|}{$\begin{array}{c}5^{\text {th }} \text { degree } \\
\text { Polynomial }\end{array}$} & \multicolumn{2}{|c|}{$\begin{array}{c}\text { G. } 5^{\text {th }} \\
\text { degree } \\
\text { Polynomial }\end{array}$} & \multicolumn{2}{|c|}{$\begin{array}{c}\text { Hradetzky } \\
\text { (1976) }\end{array}$} & \multicolumn{2}{|c|}{$\begin{array}{c}\text { G. } \\
\text { Hradetzky } \\
(1976)\end{array}$} & \multicolumn{2}{|c|}{$\begin{array}{l}\text { Kozak } \\
(2004)\end{array}$} & \multicolumn{2}{|c|}{$\begin{array}{c}\text { G. Kozak } \\
\text { (2004) }\end{array}$} & \multicolumn{2}{|c|}{$\begin{array}{c}\text { Max and } \\
\text { Burkhart } \\
(1976)\end{array}$} & \multicolumn{2}{|c|}{$\begin{array}{c}\text { G. Max and } \\
\text { Burkhart } \\
(1976)\end{array}$} & \multicolumn{2}{|c|}{ PMS } & \multicolumn{2}{|c|}{ G. PMS } \\
\hline & & dob & vol & dob & vol & dob & vol & dob & vol & dob & vol & dob & vol & dob & vol & dob & vol & dob & vol & dob & vol \\
\hline \multirow{3}{*}{1} & $\mathrm{~T}(\%)$ & 7 & 10 & 3 & 1 & 5 & 9 & 2 & 4 & 8 & 7 & 5 & 2 & 10 & 5 & 9 & 3 & 4 & 5 & 1 & 8 \\
\hline & MAE (\%) & 3 & 8 & 4 & 10 & 8 & 7 & 7 & 6 & 5 & 1 & 6 & 2 & 9 & 5 & 10 & 9 & 2 & 3 & 1 & 4 \\
\hline & RMSE & 6 & 8 & 8 & 5 & 8 & 8 & 6 & 5 & 1 & 2 & 3 & 2 & 5 & 8 & 8 & 7 & 2 & 2 & 3 & 1 \\
\hline \multirow{3}{*}{2} & $\mathrm{~T}(\%)$ & 5 & 1 & 10 & 9 & 3 & 5 & 8 & 10 & 1 & 3 & 9 & 7 & 4 & 4 & 2 & 8 & 7 & 2 & 6 & 6 \\
\hline & MAE (\%) & 5 & 6 & 6 & 9 & 9 & 5 & 7 & 8 & 3 & 4 & 4 & 3 & 10 & 6 & 8 & 10 & 2 & 1 & 1 & 2 \\
\hline & RMSE & 8 & 3 & 10 & 6 & 6 & 3 & 5 & 6 & 2 & 3 & 4 & 6 & 7 & 6 & 8 & 6 & 2 & 1 & 1 & 1 \\
\hline \multirow{3}{*}{3} & $\mathrm{~T}(\%)$ & 5 & 3 & 6 & 7 & 1 & 2 & 8 & 5 & 3 & 6 & 7 & 10 & 9 & 1 & 10 & 8 & 2 & 4 & 4 & 9 \\
\hline & MAE (\%) & 5 & 8 & 8 & 10 & 4 & 6 & 7 & 7 & 2 & 5 & 6 & 3 & 9 & 2 & 10 & 9 & 1 & 1 & 3 & 3 \\
\hline & RMSE & 8 & 6 & 10 & 9 & 6 & 6 & 5 & 9 & 2 & 1 & 1 & 1 & 6 & 5 & 9 & 6 & 2 & 1 & 2 & 1 \\
\hline \multirow{3}{*}{4} & $\mathrm{~T}(\%)$ & 1 & 6 & 7 & 9 & 6 & 5 & 9 & 7 & 4 & 2 & 8 & 8 & 5 & 3 & 10 & 10 & 2 & 4 & 3 & 1 \\
\hline & MAE (\%) & 6 & 1 & 7 & 8 & 9 & 2 & 5 & 7 & 1 & 6 & 2 & 10 & 8 & 3 & 10 & 9 & 3 & 5 & 4 & 4 \\
\hline & RMSE & 5 & 2 & 9 & 8 & 7 & 2 & 7 & 8 & 2 & 10 & 1 & 6 & 2 & 2 & 9 & 5 & 5 & 6 & 2 & 1 \\
\hline \multicolumn{2}{|c|}{ Total } & 64 & 62 & 88 & 91 & 72 & 60 & 76 & 82 & 34 & 50 & 56 & 60 & 84 & 50 & 103 & 90 & 34 & 35 & 31 & 41 \\
\hline
\end{tabular}

Vol: individual tree volume $\left(\mathrm{m}^{3}\right)$; G.: Generalized 
Table 4. Accuracy statistics (T, MAE and RMSE) applied to evaluate the individual tree volume $\left(\mathrm{m}^{3}\right)$ estimation for the taper functions with the dataset stratified (trees with $\mathrm{DBH}<33^{\text {th }}$ quantile; trees with $\mathrm{DBH}>33^{\text {th }}$ and $<67^{\text {th }}$ quantile; trees with $\mathrm{DBH}>67^{\text {th }}$ quantile).

\begin{tabular}{|c|c|c|c|c|c|c|c|c|c|c|}
\hline \multirow[b]{2}{*}{$\begin{array}{l}\text { Genetic } \\
\text { family }\end{array}$} & \multirow[b]{2}{*}{ Taper functions } & \multicolumn{3}{|c|}{ DBH $<33$ th quantile } & \multicolumn{3}{|c|}{ 33th $<$ DBH $<67$ th quantile } & \multicolumn{3}{|c|}{ DBH $>67$ th quantile } \\
\hline & & $\mathrm{T}(\%)$ & $\begin{array}{c}\text { MAE } \\
(\%)\end{array}$ & $\operatorname{RMSE}\left(\mathbf{m}^{3}\right)$ & $\mathrm{T}(\%)$ & $\begin{array}{c}\text { MAE } \\
(\%)\end{array}$ & $\operatorname{RMSE}\left(\mathrm{m}^{3}\right)$ & $\mathrm{T}(\%)$ & $\begin{array}{c}\text { MAE } \\
(\%)\end{array}$ & $\operatorname{RMSE}\left(\mathbf{m}^{3}\right)$ \\
\hline \multirow{10}{*}{1} & $5^{\text {th }}$ degree Polynomial & -2.32 & 5.09 & 0.019 & -1.23 & 4.13 & 0.019 & -1.32 & 4.61 & 0.017 \\
\hline & $\begin{array}{l}\text { G. } 5^{\text {th }} \text { degree } \\
\text { Polynomial }\end{array}$ & -1.21 & 5.28 & 0.017 & 0.24 & 4.35 & 0.017 & 0.88 & 4.34 & 0.015 \\
\hline & Hradetzky (1976) & -2.13 & 5.06 & 0.018 & -1.01 & 4.13 & 0.018 & -0.74 & 4.47 & 0.016 \\
\hline & G. Hradetzky (1976) & -0.75 & 5.00 & 0.017 & 0.46 & 4.19 & 0.017 & 0.74 & 4.34 & 0.016 \\
\hline & Kozak (2004) & -1.53 & 4.46 & 0.014 & -0.54 & 3.86 & 0.015 & -0.91 & 4.47 & 0.015 \\
\hline & G. Kozak (2004) & -0.97 & 4.65 & 0.014 & 0.19 & 3.89 & 0.015 & 0.44 & 4.32 & 0.015 \\
\hline & $\begin{array}{c}\text { Max and Burkhart } \\
(1976)\end{array}$ & -1.67 & 4.78 & 0.019 & -0.63 & 4.01 & 0.019 & -0.57 & 4.43 & 0.016 \\
\hline & $\begin{array}{l}\text { G. Max and Burkhart } \\
(1976)\end{array}$ & -1.04 & 5.19 & 0.018 & 0.34 & 4.36 & 0.018 & 1.03 & 4.35 & 0.015 \\
\hline & PMS & -1.40 & 4.42 & 0.015 & -0.46 & 3.94 & 0.015 & -0.99 & 4.48 & 0.015 \\
\hline & Full PMS & -1.77 & 4.64 & 0.014 & -0.65 & 3.88 & 0.015 & -0.99 & 4.50 & 0.015 \\
\hline \multirow{10}{*}{2} & $5^{\text {th }}$ degree Polynomial & -0.85 & 4.97 & 0.017 & 0.66 & 4.19 & 0.014 & 0.08 & 4.34 & 0.014 \\
\hline & $\begin{array}{l}\text { G. } 5^{\text {th }} \text { degree } \\
\text { Polynomial }\end{array}$ & 0.83 & 4.94 & 0.017 & 2.20 & 4.54 & 0.015 & 1.59 & 4.66 & 0.015 \\
\hline & Hradetzky (1976) & -0.66 & 4.88 & 0.017 & 0.91 & 4.17 & 0.014 & 0.35 & 4.36 & 0.014 \\
\hline & G. Hradetzky (1976) & 1.13 & 4.88 & 0.017 & 2.35 & 4.46 & 0.015 & 1.83 & 4.67 & 0.015 \\
\hline & Kozak (2004) & -1.13 & 4.62 & 0.015 & 0.50 & 4.32 & 0.015 & -0.05 & 4.30 & 0.014 \\
\hline & G. Kozak (2004) & 0.41 & 4.22 & 0.016 & 1.85 & 4.43 & 0.016 & 1.24 & 4.27 & 0.016 \\
\hline & $\begin{array}{c}\text { Max and Burkhart } \\
(1976)\end{array}$ & -0.72 & 4.93 & 0.018 & 0.87 & 4.22 & 0.015 & 0.26 & 4.33 & 0.015 \\
\hline & $\begin{array}{l}\text { G. Max and Burkhart } \\
(1976)\end{array}$ & 0.73 & 4.97 & 0.018 & 2.16 & 4.57 & 0.016 & 1.52 & 4.66 & 0.016 \\
\hline & $\begin{array}{c}\text { PMS } \\
\end{array}$ & -1.08 & 4.59 & 0.016 & 0.58 & 4.14 & 0.014 & 0.03 & 4.09 & 0.014 \\
\hline & Full PMS & -1.08 & 4.76 & 0.016 & -0.16 & 4.12 & 0.013 & -0.66 & 4.06 & 0.013 \\
\hline \multirow{8}{*}{3} & $5^{\text {th }}$ degree Polynomial & -1.54 & 5.13 & 0.017 & -1.77 & 4.67 & 0.022 & -0.22 & 4.91 & 0.015 \\
\hline & $\begin{array}{l}\text { G. } 5^{\text {th }} \text { degree } \\
\text { Polynomial }\end{array}$ & -1.78 & 5.06 & 0.018 & -2.24 & 4.90 & 0.023 & -0.67 & 4.84 & 0.015 \\
\hline & Hradetzky (1976) & -1.33 & 5.05 & 0.017 & -1.58 & 4.62 & 0.022 & 0.01 & 4.84 & 0.015 \\
\hline & G. Hradetzky (1976) & -1.63 & 4.98 & 0.018 & -1.99 & 4.91 & 0.023 & -0.44 & 4.74 & 0.015 \\
\hline & Kozak (2004) & -1.61 & 5.01 & 0.015 & -2.11 & 4.83 & 0.017 & -0.76 & 4.63 & 0.015 \\
\hline & $\begin{array}{c}\text { G. Max and Burkhart } \\
(1976)\end{array}$ & -1.73 & 4.96 & 0.017 & -2.31 & 4.95 & 0.022 & -0.72 & 4.86 & 0.015 \\
\hline & PMS & -1.33 & 4.89 & 0.015 & -1.63 & 4.59 & 0.017 & -0.61 & 4.69 & 0.014 \\
\hline & G. PMS & -1.68 & 4.95 & 0.015 & -2.02 & 4.74 & 0.018 & -1.04 & 4.77 & 0.014 \\
\hline \multirow{10}{*}{4} & $5^{\text {th }}$ degree Polynomial & 2.31 & 5.19 & 0.015 & 2.07 & 4.44 & 0.012 & 3.22 & 4.43 & 0.011 \\
\hline & $\begin{array}{l}\text { G. } 5^{\text {th }} \text { degree } \\
\text { Polynomial }\end{array}$ & -5.56 & 7.02 & 0.018 & -4.94 & 6.41 & 0.017 & -3.42 & 5.24 & 0.012 \\
\hline & Hradetzky (1976) & 2.26 & 5.23 & 0.015 & 1.75 & 4.42 & 0.012 & 3.15 & 4.43 & 0.011 \\
\hline & G. Hradetzky (1976) & -5.27 & 6.78 & 0.018 & -4.20 & 5.96 & 0.017 & -3.61 & 5.34 & 0.012 \\
\hline & Kozak (2004) & 1.99 & 5.64 & 0.020 & 1.71 & 4.69 & 0.017 & 2.55 & 4.73 & 0.014 \\
\hline & G. Kozak (2004) & -5.03 & 7.02 & 0.015 & -4.79 & 6.39 & 0.013 & -4.47 & 5.89 & 0.010 \\
\hline & $\begin{array}{c}\text { Max and Burkhart } \\
(1976)\end{array}$ & 2.01 & 5.34 & 0.014 & 1.74 & 4.42 & 0.012 & 2.66 & 4.50 & 0.010 \\
\hline & $\begin{array}{l}\text { G. Max and Burkhart } \\
\text { (1976) }\end{array}$ & -5.65 & 7.03 & 0.018 & -5.06 & 6.51 & 0.017 & -3.89 & 5.45 & 0.011 \\
\hline & PMS & 2.06 & 5.44 & 0.018 & 1.69 & 4.61 & 0.015 & 2.62 & 4.77 & 0.013 \\
\hline & G. PMS & 1.46 & 5.39 & 0.014 & -0.67 & 4.69 & 0.012 & -0.21 & 4.39 & 0.009 \\
\hline
\end{tabular}

G.: Generalized 
Table 5. Ranking of various approaches examined to evaluate the taper function that best described individual tree volume $\left(\mathrm{m}^{3}\right)$ for all the genetic families with the dataset stratified.

\begin{tabular}{|c|c|c|c|c|c|c|c|c|c|c|c|}
\hline \multirow{2}{*}{ GF } & \multirow{2}{*}{ Stat. } & Pol & G. Pol & Hra & G. Hra & Koz & G. Koz & MB & G. MB & PMS & G. PMS \\
\hline & & \multicolumn{10}{|c|}{ DBH $<$ 33th quantile } \\
\hline \multirow{3}{*}{1} & $\mathrm{~T}$ & 10 & 4 & 9 & 1 & 6 & 2 & 7 & 3 & 5 & 8 \\
\hline & MAE & 8 & 10 & 7 & 6 & 2 & 4 & 5 & 9 & 1 & 3 \\
\hline & RMSE & 9 & 5 & 7 & 5 & 1 & 1 & 9 & 7 & 4 & 1 \\
\hline \multirow{3}{*}{2} & $\mathrm{~T}$ & 6 & 5 & 2 & 9 & 9 & 1 & 3 & 4 & 7 & 7 \\
\hline & MAE & 9 & 8 & 5 & 5 & 3 & 1 & 7 & 9 & 2 & 4 \\
\hline & RMSE & 5 & 5 & 5 & 5 & 1 & 2 & 9 & 9 & 2 & 2 \\
\hline \multirow{3}{*}{3} & $\mathrm{~T}$ & 4 & 10 & 2 & 6 & 5 & 8 & 1 & 9 & 2 & 7 \\
\hline & MAE & 10 & 9 & 8 & 6 & 7 & 2 & 4 & 4 & 1 & 3 \\
\hline & RMSE & 6 & 9 & 6 & 9 & 1 & 1 & 5 & 6 & 1 & 1 \\
\hline \multirow{3}{*}{4} & $\mathrm{~T}$ & 6 & 9 & 5 & 8 & 2 & 7 & 3 & 10 & 4 & 1 \\
\hline & MAE & 1 & 8 & 2 & 7 & 6 & 8 & 3 & 10 & 5 & 4 \\
\hline & RMSE & 3 & 6 & 3 & 6 & 10 & 3 & 1 & 6 & 6 & 1 \\
\hline \multicolumn{2}{|c|}{ Total } & 77 & 88 & 61 & 73 & 53 & 40 & 57 & 86 & 40 & 42 \\
\hline & & \multicolumn{10}{|c|}{ 33th $<$ DBH $<67$ th quantile } \\
\hline \multirow{3}{*}{1} & $\mathrm{~T}$ & 10 & 2 & 9 & 4 & 6 & 1 & 7 & 3 & 4 & 8 \\
\hline & MAE & 6 & 9 & 6 & 8 & 1 & 3 & 5 & 10 & 4 & 2 \\
\hline & RMSE & 9 & 5 & 7 & 5 & 1 & 1 & 9 & 7 & 1 & 1 \\
\hline \multirow{3}{*}{2} & $\mathrm{~T}$ & 4 & 9 & 6 & 10 & 2 & 7 & 5 & 8 & 3 & 1 \\
\hline & MAE & 4 & 9 & 3 & 8 & 6 & 7 & 5 & 10 & 2 & 1 \\
\hline & RMSE & 2 & 5 & 2 & 5 & 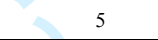 & 9 & 5 & 9 & 2 & 1 \\
\hline \multirow{3}{*}{3} & $\mathrm{~T}$ & 4 & 8 & 2 & 5 & 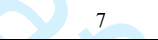 & 10 & 1 & 9 & 3 & 6 \\
\hline & MAE & 4 & 7 & 3 & 8 & 6 & 10 & 2 & 9 & 1 & 5 \\
\hline & RMSE & 6 & 9 & 6 & 9 & 1 & 3 & 5 & 6 & 1 & 3 \\
\hline \multirow{3}{*}{4} & $\mathrm{~T}$ & 6 & 9 & 5 & 7 & 3 & 8 & 4 & 10 & 2 & 1 \\
\hline & MAE & 3 & 9 & 1 & 7 & 5 & 8 & 1 & 10 & 4 & 5 \\
\hline & RMSE & 1 & 7 & 1 & 7 & 7 & 5 & 1 & 7 & 6 & 1 \\
\hline & & 59 & 88 & 51 & 83 & 50 & 72 & 50 & 98 & 33 & 35 \\
\hline & & \multicolumn{10}{|c|}{ DBH $>67$ th quantile } \\
\hline & $\mathrm{T}$ & 10 & 5 & 3 & 3 & 6 & 1 & 2 & 9 & 7 & 7 \\
\hline \multirow[t]{3}{*}{1} & MAE & 10 & 2 & 6 & 2 & 6 & 1 & 5 & 4 & 8 & 9 \\
\hline & RMSE & 10 & 1 & 7 & 7 & 1 & 1 & 7 & 1 & 1 & 1 \\
\hline & $\mathrm{T}$ & 3 & 9 & 5 & 10 & 2 & 7 & 4 & 8 & 1 & 6 \\
\hline \multirow[t]{3}{*}{2} & MAE & 6 & 8 & 7 & 10 & 4 & 3 & 5 & 8 & 2 & 1 \\
\hline & RMSE & 2 & 6 & 2 & 6 & 2 & 9 & 6 & 9 & 2 & 1 \\
\hline & $\mathrm{T}$ & 3 & 6 & 1 & 4 & 8 & 9 & 2 & 7 & 5 & 10 \\
\hline \multirow[t]{3}{*}{3} & MAE & 10 & 6 & 6 & 4 & 2 & 1 & 8 & 8 & 3 & 5 \\
\hline & RMSE & 4 & 4 & 4 & 4 & 4 & 1 & 4 & 4 & 2 & 2 \\
\hline & $\mathrm{T}$ & 6 & 7 & 5 & 8 & 2 & 10 & 4 & 9 & 3 & 1 \\
\hline \multirow[t]{2}{*}{4} & MAE & 2 & 7 & 2 & 8 & 5 & 10 & 4 & 9 & 6 & 1 \\
\hline & RMSE & 4 & 7 & 4 & 7 & 10 & 2 & 2 & 4 & 9 & 1 \\
\hline \multicolumn{2}{|c|}{ Total } & 70 & 68 & 52 & 73 & 52 & 55 & 53 & 80 & 49 & 45 \\
\hline
\end{tabular}

GF: Genetic Family; Stat.: Statistics; G: Generalized; Pol: $5^{\text {th }}$ degree polynomial; F Pol: Full $5^{\text {th }}$ degree polynomial; Hra: Hradetzky (1976); F Hra: Full Hradetzky (1976); Koz: Kozak (2004); F Koz: Full Kozak (2004); MB: Max and Burkhart (1976); F MB: Full Max and Burkhart (1976); F PMS: Full PMS. 
Table 6. Average accuracy statistics (T, MAE and RMSE) and their confidence intervals at $95 \%$ confidence level applied to evaluate the individual tree volume $\left(\mathrm{m}^{3}\right)$.

\begin{tabular}{cccc}
\hline \multirow{2}{*}{ Statistics } & \multirow{2}{*}{ Mean } & \multicolumn{2}{c}{ Confidence Interval (95 \%) } \\
\cline { 3 - 4 } & & Lower & Upper \\
\hline T $(\%)$ & -1.09 & -1.32 & -0.85 \\
MAE $(\%)$ & 4.53 & 4.32 & 4.68 \\
RMSE $\left(\mathrm{m}^{3}\right)$ & 0.015 & 0.014 & 0.016 \\
\hline
\end{tabular}


Figure 1. Location of sampled Eucalyptus stands in Água Clara, MS.

Figure 2. Comparison of examined taper approaches for predicting stem taper of genetic family 1.

Figure 3. Residual plot with lowess trendlines to verify performances of various approaches for predicted volume across stem height for genetic families.

Figure 4. Overall sampling distribution of the accuracy statistics T, MAE and RMSE.

Figure 5. Residual plot with lowess trendlines to verify performances of PMS approaches with and without the variable tree size. 


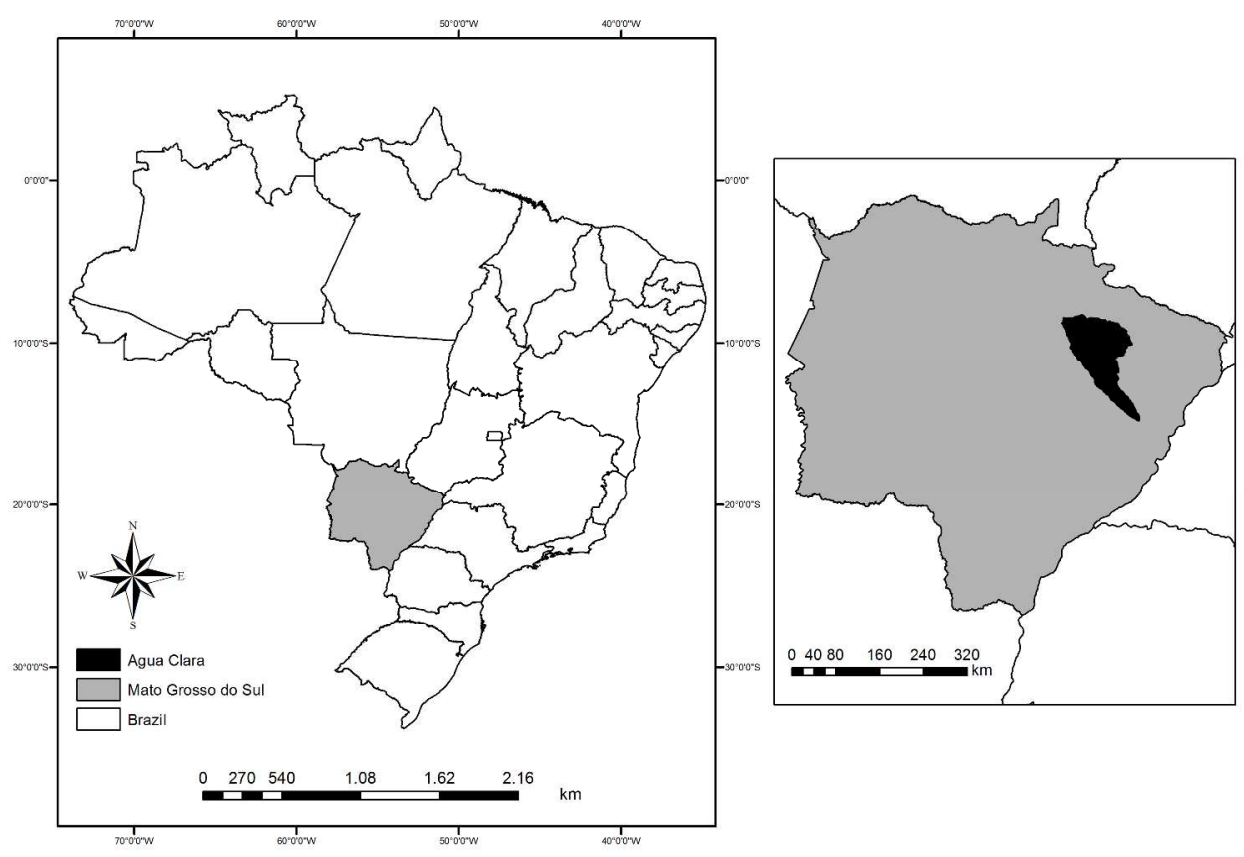

Figure 1. Location of sampled Eucalyptus stands in Água Clara, MS.

$297 \times 210 \mathrm{~mm}(300 \times 300$ DPI $)$ 

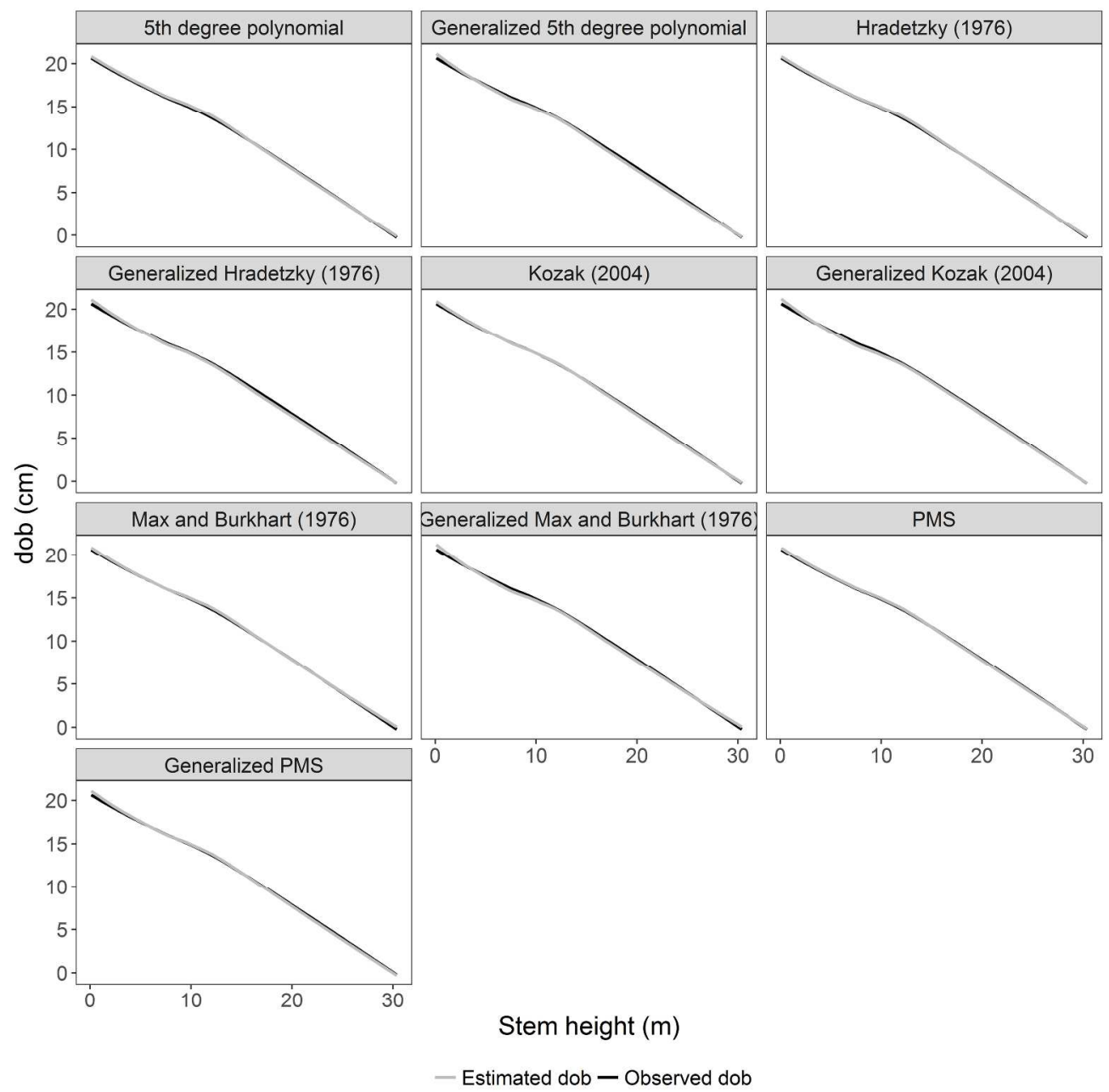

0

Figure 2. Comparison of examined taper approaches for predicting stem taper of genetic family 1 . $259 \times 259 \mathrm{~mm}(300 \times 300 \mathrm{DPI})$ 


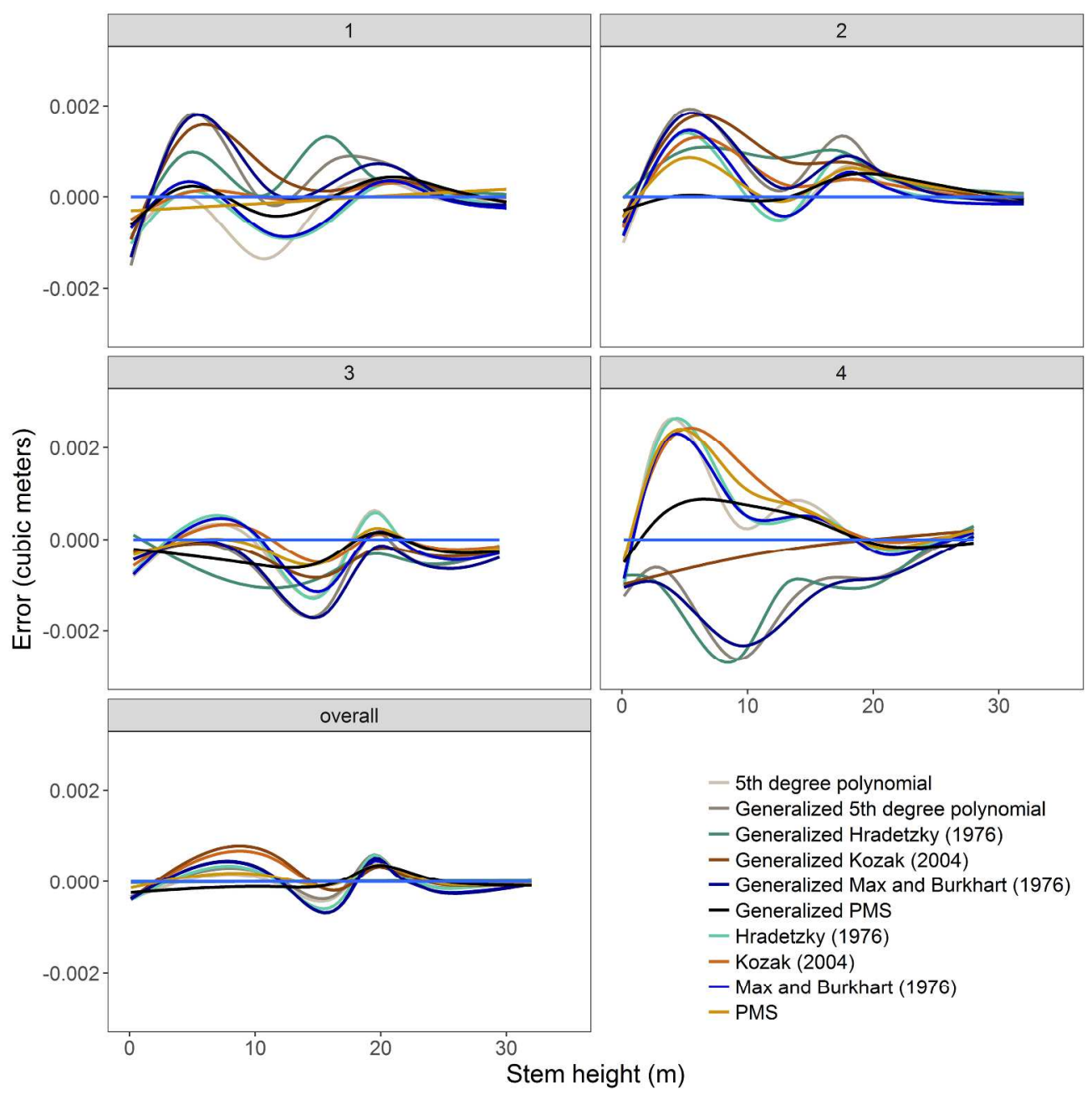

Figure 3. Residual plot with lowess trendlines to verify performances of various approaches for predicted volume across stem height for genetic families.

$259 \times 259 \mathrm{~mm}(300 \times 300 \mathrm{DPI})$ 

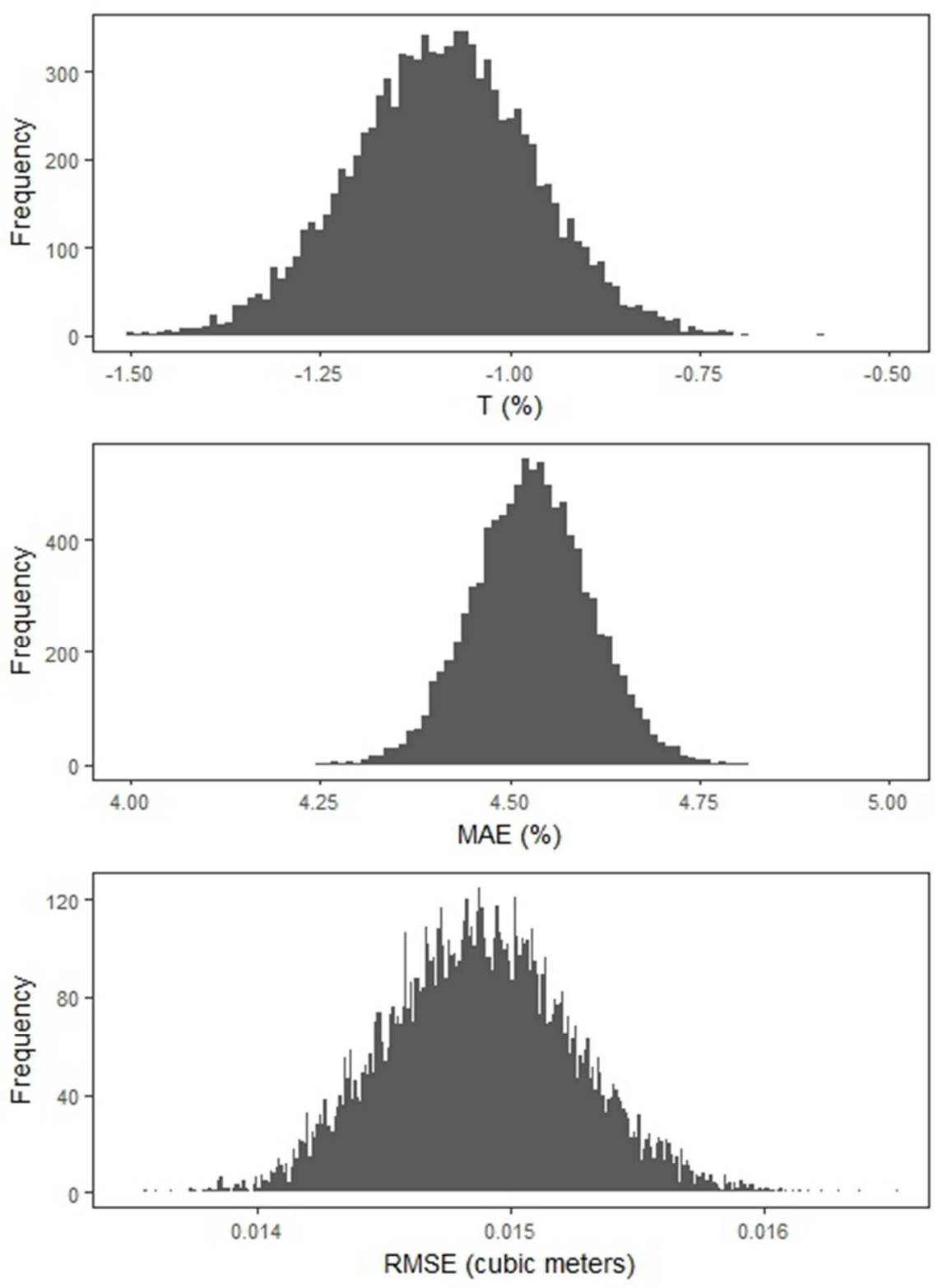

Figure 4. Overall sampling distribution of the accuracy statistics T, MAE and RMSE. $176 \times 239 \mathrm{~mm}(72 \times 72$ DPI $)$ 


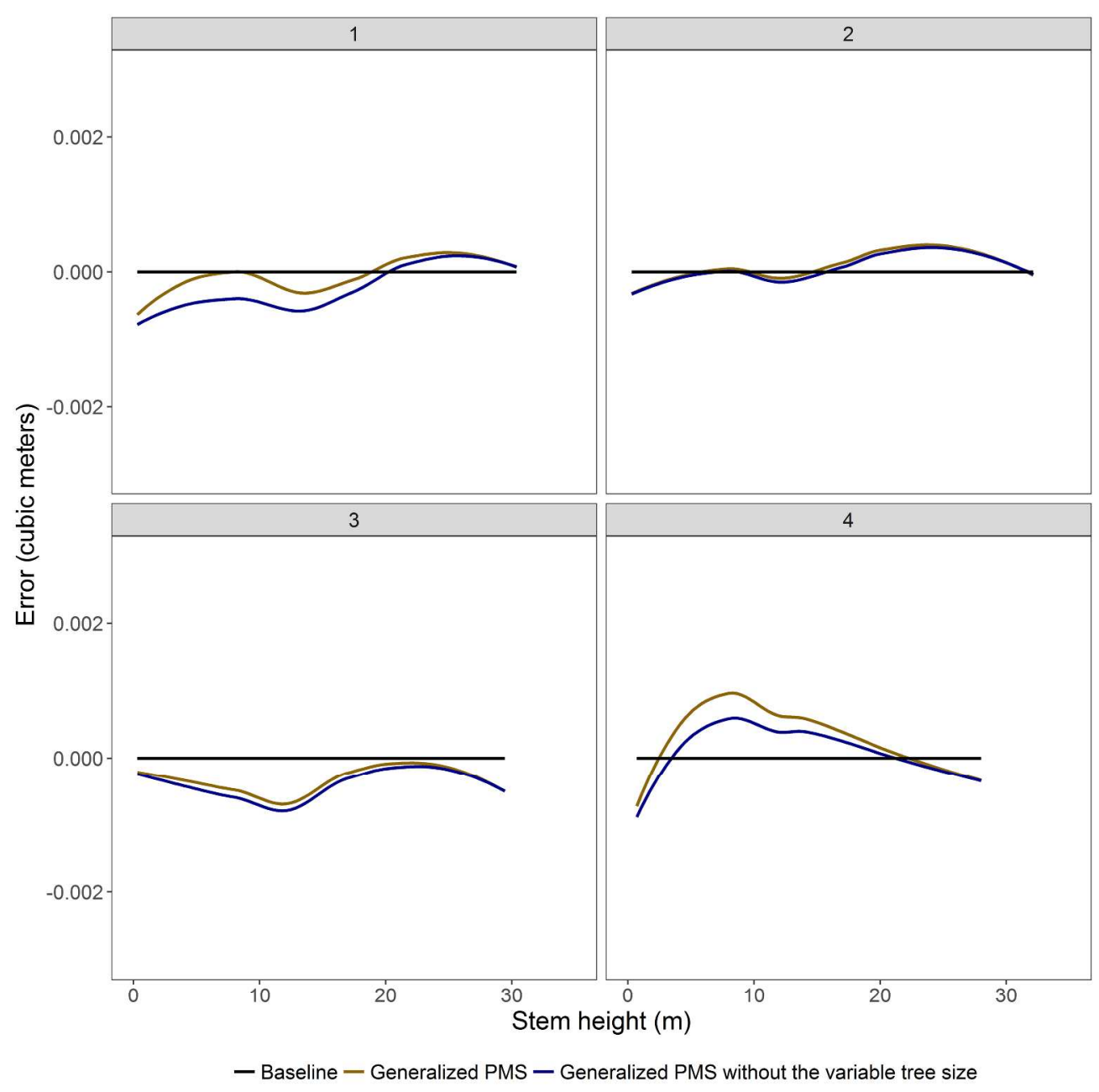

Figure 5. Residual plot with lowess trendlines to verify performances of PMS approaches with and without the variable tree size.

$259 \times 259 \mathrm{~mm}(300 \times 300 \mathrm{DPI})$ 